\title{
Indeterminacy, Aggregate Demand, and the Real Business Cycle*
}

\author{
Jess Benhabib \\ Department of Economics \\ New York University \\ jess.benhabib@nyu.edu
}

\author{
Yi Wen \\ Department of Economics \\ Cornell University \\ Yw57@cornell.edu
}

January 31, 2002

\begin{abstract}
We show that under indeterminacy aggregate demand shocks are able to explain not only aspects of actual fluctuations that standard RBC models predict fairly well, but also aspects of actual fluctuations that standard RBC models cannot explain, such as the hump-shaped, trend reverting impulse responses to transitory shocks found in US output (Cogley and Nason, AER, 1995); the large forecastable movements and comovements of output, consumption and hours (Rotemberg and Woodford, AER, 1996); and the fact that consumption appears to lead output and investment over the business cycle. Indeterminacy arises in our model due to capacity utilization and mild increasing returns to scale.
\end{abstract}

\footnotetext{
${ }^{*}$ We wish to thank Jordi Gali, Stephanie Schmitt-Grohé, Karl Shell, and Martin Uribe for very useful discussions and comments. Technical support from the C.V. Starr Center for Applied Economics at New York University and the Center for Analytical Economics at Cornell University is gratefully acknowledged.
} 


\section{Introduction}

General equilibrium real business cycle models have been subject to a number of criticisms. A basic criticism is the heavy reliance of such models on technology shocks to explain business cycle facts (for example, Blanchard, 1989 and 1993; Cochrane, 1994; Evans, 1992; Gordon, 1993; Mankiw, 1989; Summers, 1986). Another is the lack of an endogenous amplification and propagation mechanism, which has resulted in the failure of standard RBC models to explain the large hump-shaped, trend-reverting output responses to transitory shocks (Cogley and Nason, 1995, Watson, 1993). ${ }^{1}$ Third, real business cycle models have been criticized for failing to match the forecastable movements and comovements of basic macroeconomic variables observed in the data (see Rotemberg and Woodford, 1996). Finally, standard RBC models cannot explain why consumption appears to lead output and investment over the business cycle.

These problems are related. From a Keynesian view point, demand shocks are thought to be important for generating business cycles because the slow adjustment in prices or wages may cause resources (such as labor or production capacity) to be underutilized, making possible the expansion of output in response to an increase in aggregate demand without significantly increasing marginal costs. In contrast, resources in standard equilibrium business cycle models are fully utilized because prices adjust quickly to clear markets. Therefore, transitory demand shocks generate a strong crowding-out effect, resulting in negative comovements among the components of aggregate demand and in having only a minimal impact on aggregate output and employment. Consequently, standard RBC models have relied on supply shocks to explain the business cycle.

Despite some empirical evidence favoring demand shocks as the main source of the business cycle (e.g., see Blanchard, 1989 and 1993; Blanchard and Quah, 1989; Cochrane, 1994; and Wen, 2002), "it is not as easy as it seems to specify a consistent dynamic model in which consumption [demand] shocks generate business-cycle fluctuations" (Cochane, 1994). The assumption of sticky prices coupled with demand shocks may not be enough to account for the propagation mechanism through which shocks to real demand generate persistent, trend reverting output dynamics. ${ }^{2}$

We show in this paper that a very simple general equilibrium model of indeterminacy (see Wen, 1998) has the potential to capture the more "Keynesian" features of the demand-driven

\footnotetext{
${ }^{1}$ Much effort has been made recently to find ways to enrich the internal propagation mechanisms of RBC models driven by technology shocks. Prominent examples include Burnside and Eichenbaum (1996), Andolfatto (1996), Carlstrom and Fuerst (1997), Bernanke, Gertler, and Gilchrist (1999), among many others.

${ }^{2}$ Monetary shocks, on the other hand, do not appear to be quantitatively important for explaining the business cycle (e.g., see Cochrane, 1994). Models with nominal rigidities can have rich propagation mechanisms to transmit monetary shocks. But real shocks in these models apparently do not lead to humpshaped output dynamics. For example, Dufourt (2000) shows that in a sticky price model monetary shocks can potentially resolve the Cogley-Nason (1995) and the Rotemberg-Woodford (1996) puzzles. But it is clear from his analysis that real shocks alone cannot do the job.
} 
business cycle without abandoning the hypotheses of market clearing and flexible prices. In particular, we show that in such a model demand shocks alone can generate predictions that are broadly consistent with a rich array of seemingly unrelated empirical business cycle "anomalies" which the traditional RBC models fail to explain. These anomalies include the hump-shaped output dynamics, the large forecastable movements and comovements found in consumption, hours, investment and output, and the fact that consumption appears to lead output and investment over the business cycle.

There are two essential elements in the model that give demand shocks a primary role for explaining business cycles in general equilibrium. The first is variable capacity utilization. The second is the presence of a small and empirically plausible externality in production. Variable capacity utilization has the effect of magnifying the marginal product of labor in the short-run by enhancing the output elasticity of labor. Coupled with a mild production externality that is consistent with recent empirical estimates, it makes the model behave as if there were increasing returns to the labor input (or as if there were unutilized resources). This factor is crucial not only because it gives rise to a multiplier that mitigates the crowding-out effect in response to demand shocks, but also because it results in an endogenous propagation mechanism essential for explaining the characteristics of forecastable movements as well as hump-shaped, trend reverting time series observed in the data.

We examine three different types of aggregate demand shocks: shocks to consumption demand, shocks to government spending, and sunspot shocks to investors' animal spirits. We find that: a) Demand shocks to either consumption, government spending, or investors' animal spirits can each generate fluctuations in output, hours, and investment that are broadly consistent with the U.S. data and are comfortably comparable to predictions of standard RBC models under technology shocks. b) Serially correlated demand shocks to either consumption or government spending can generate hump-shaped impulse responses for output, investment and hours. c) Demand shocks to either consumption, government spending, or investor's animal spirits are able to induce large forecastable movements in consumption, investment, hours, and output that are broadly consistent with the findings of Rotemberg and Woodford (1996). ${ }^{3}$ d) When the main source of shocks comes from consumption demand, the model is able to generate consumption series that leads both output and investment over the business cycle.

The rest of the paper is organized as follows. Section 2 explains the model. Section 3 presents the predictions of the model with respect to conventional simple measures of the business cycle. Section 4 addresses the Cogley-Nason criticism of RBC models. Section 5 addresses the Rotemberg-Woodford criticism of RBC models. Section 6 addresses the puzzle that consumption appears to lead the business cycle, and section 7 concludes.

\footnotetext{
${ }^{3}$ Using a two-sector RBC model of indeterminacy, Schmitt-Grohe (2000) shows that sunspot shocks are capable of generating forecastable movements in output, hours, and investment that are broadly consistent with the US data. But she also shows that sunspot shocks tend to generate the wrong comovements for expected changes in consumption and output. In this paper, we show that sunspot shocks in our onesector RBC model of indeterminacy can generate positive correlations between forecastable movement in consumption and forecastable movement in output.
} 


\section{The Model}

This is the one-sector RBC model studied by Wen (1998), based on Benhabib and Farmer (1994). A representative agent in the model chooses sequences of consumption, hours, capacity utilization, and capital accumulation to solve

$$
\max E_{0} \sum_{t=0}^{\infty} \beta^{t}\left(\log \left(c_{t}-\Delta_{t}\right)-a \frac{n_{t}^{1+\gamma}}{1+\gamma}\right)
$$

subject to

$$
c_{t}+i_{t}+g_{t}=\Phi_{t}\left(e_{t} k_{t}\right)^{\alpha} n_{t}^{(1-\alpha)}
$$

$k_{t+1}=i_{t}+\left(1-\delta_{t}\right) k_{t}$; where $\Delta_{t}$ is a random shock to consumption that generates the urge to consume (see Baxter and King, 1991); $g_{t}$ is a shock to government spending, representing a pure resource drain on the economy; $e \in[0,1]$ denotes capital utilization rate, and $\Phi$ is a measure of production externalities and is defined as a function of average aggregate output which individuals take as parametric:

$$
\Phi=\left[(e k)^{\alpha} n^{1-\alpha}\right]^{\eta}, \quad \eta \geq 0 .
$$

When the externality parameter $\eta$ is zero, the model reduces to a standard RBC model studied by Greenwood et al. (1988) and Burnside and Eichenbaum (1996). To have an interior solution for $e$ in the steady state, we follow Greenwood et al. by assuming that the capital stock depreciates faster if it is used more intensively:

$$
\delta_{t}=\lambda e_{t}^{\theta}, \quad \theta>1
$$

which imposes a convex cost structure on capital utilization. ${ }^{4}$

\footnotetext{
${ }^{4}$ The externality model can also be cast as a monopolistic competition model with mild increasing returns to scale at the individual firm level. The final output sector is defined as$$
Y=\left[\int y(i)^{\lambda} d i\right]^{\frac{1}{\lambda}}
$$

and the intermediate commodity $y(i)$ is given by

$$
y(i)=[e(i) k(i)]^{a} n(i)^{b},
$$

Then the aggregate production function in the model has the reduced form:

$$
y=(e k)^{a} n^{b} .
$$

The markup is defined as the logarithm of price-marginal cost ratio:

$$
\mu=\ln \frac{1}{1+(\lambda-1)},
$$

where $(\lambda-1)$ is the inverse of the price elasticity of demand facing an intermediate goods producing firm. For the monopolistic competition model to be exactly equivalent to the externality model, we simply set $\lambda a=\alpha$, $\lambda b=1-\alpha$, and $a+b=1+\eta$. This implies that $\lambda=\frac{1}{a+b}=\frac{1}{1+\eta}$. The markup is therefore given by $\mu \simeq \eta$ Since the model requires only a very mild externality $\eta$ in the order around 0.11 to generate indeterminacy, the markup $(\mu)$ required in the corresponding monopolistic version of the model is also very mild.
} 
To solve the model, we log-linearize the first order conditions around the steady state as in King et al. (1988). To study investors' "animal spiritś" as a possible source of aggregate demand uncertainty, we arrange the system of linearized equations in a way such that investment rather than the Lagrangian multiplier appears in the state vector. Denoting $S_{t}$ as the vector $\left(k_{t}, i_{t}\right)^{\prime}$, disregarding the fundamental shock variables for a moment, the model can be reduced to the following system of linear difference equations (hat-variables denote percentage deviations from their steady state values):

$$
\begin{aligned}
\hat{S}_{t+1} & =W \hat{S}_{t}+R \Theta_{t+1}, \\
\hat{Z}_{t} & =H \hat{S}_{t}
\end{aligned}
$$

where $\Theta_{t+1}$ is a $2 \times 1$ vector of one-step ahead forecasting errors given by

$$
\Theta_{t+1}=\hat{S}_{t+1}-E_{t} \hat{S}_{t+1}=\left(\begin{array}{c}
\hat{k}_{t+1}-E_{t} \hat{k}_{t+1} \\
\hat{\imath}_{t+1}-E_{t} \hat{\imath}_{t+1}
\end{array}\right)
$$

satisfying

$$
E_{t} \Theta_{t+1}=0
$$

and $\hat{Z}_{t}$ is a vector of any other endogenous variables in the model. Notice that the first element in $\Theta_{t}$ is 0 since $\hat{k}_{t+1}$ is known at the beginning of period $t$. Define the second element in $\Theta_{t}$ as $v_{s t}=\hat{\imath}_{t}-E_{t-1} \hat{\imath}_{t}$.

When the model has a unique equilibrium (i.e., one of the eigenvalues of $W$ lies outside the unit circle), the optimal decision rule for investment does not depend on the forecasting error, $v_{s t}$, since in that case $\hat{\imath}_{t}$ can be solved forward under the expectation operator $E_{t}$ to eliminate any forecasting errors associated with future investment. Consequently, the optimal decision rules at $t$ depend only on the current capital stock $\left(\hat{k}_{t}\right)$. If both eigenvalues of $W$ lie inside the unit circle, however, the model is indeterminate in the sense that any value of $\hat{\imath}_{t}$ is consistent with equilibrium given $\hat{k}_{t}$. Hence, the forecasting error $v_{s t}$ can play a role in determining the equilibrium level of investment. ${ }^{5}$ In particular, under indeterminacy the decision rule for investment at time $t$ takes the special form:

$$
\hat{\imath}_{t}=\omega_{21} \hat{k}_{t-1}+\omega_{22} \hat{\imath}_{t-1}+r_{2} v_{s t},
$$

where $\omega_{21}, \omega_{22}$, and $r_{2}$ are the second row elements in $W$ and $R$ respectively.

The condition, $E_{t} v_{s t+1}=0$, implies that rational agents do not make systematic errors in forecasting the future based on current information. Since $v_{s t}$ can reflect purely extraneous shocks, it can be interpreted as shocks to autonomous investment. ${ }^{6}$ There are therefore three possible types of aggregate demand disturbances in the model: innovations to government spending $\varepsilon_{g}$, innovations to consumption demand $\varepsilon_{\Delta}$, and innovations to autonomous investment $v_{s}$.

\footnotetext{
${ }^{5}$ For more discussions on this issue, see Farmer (1999) and Farmer and Guo (1994).

${ }^{6}$ But $v_{s}$ can also reflect innovations in the fundamentals. When this is the case, we say that sunspots are correlated with fundamental shocks.
} 
Following the existing literature, we calibrate our model by setting the time interval to be a quarter, the discount factor $\beta=0.99$, the capital's share $\alpha=0.3$, the inverse elasticity of labor supply $\gamma=0$ (Hansen's (1988) indivisible labor), and we choose $\theta$ such that the rate of capital depreciation in the steady state is 10 percent a year (implying $\delta=0.025$ in the steady state and $\theta \approx 1.4$ ). The steady state value of $\Delta$ is chosen so that the ratio, $\frac{\Delta}{c}$, is 0.1 in the steady state. Also, the steady state government spending to output ratio is set at $\frac{g}{y}=0.2$ (consistent with post-war U.S. data). ${ }^{7}$ The minimum degree of the externality $\eta$ required for indeterminacy is 0.104 . We calibrate $\eta$ with a value of 0.11 so that the implied frequency of cycles in the model roughly mathces that of the U.S. economy. This value of $\eta$ implies a markup around 0.1 or a degree of aggregate returns to scale around 1.1, which, based on recent empirical studies (e.g., Basu and Fernald, 1997; and Burnside et al., 1995) is in the empirically plausible range. ${ }^{8}$ Notice that the aggregate labor demand curve is downward sloping when indeterminacy arises in the model, which is in sharp contrast to models with fixed capacity utilization. ${ }^{9}$

With variable capacity utilization, the effective returns to labor can exceed one even though the labor-output elasticity, $(1-\alpha)(1+\eta)$, is substantially less than one. To illustrate this, we derive a reduced-form aggregate production function evaluated at the optimal rate of capacity utilization: ${ }^{10}$

$$
y_{t}=q k_{t}^{\alpha(1+\eta) \tau_{k}} n_{t}^{(1-\alpha)(1+\eta) \tau_{n}}
$$

where $q$ is a constant and $t_{k}$ and $t_{n}$ are defined as

$$
\tau_{k}=\frac{\theta-1}{\theta-\alpha(1+\eta)}, \tau_{n}=\frac{\theta}{\theta-\alpha(1+\eta)} .
$$

Stationarity requires that $\alpha(1+\eta)<1$, hence we have $\tau_{k}<1$ and $\tau_{n}>1$, because $\theta>1$. The reduced-form aggregate production function evaluated at the optimal capacity utilization rate effectively amplifies labor's elasticity of output, as if there were increasing returns to the labor, even though the true returns to labor, $(1-\alpha)(1+\eta)$, are less than one. For example, given $\alpha=0.3, \beta=0.99, \delta=0.025, \eta=0.11$, the true labor-output elasticity is $(1-\alpha)(1+\eta) \approx 0.78$, but the effective labor-output elasticity (taking into account optimal capacity utilization) is $(1-\alpha)(1+\eta) \tau_{n} \approx 1.02$.

We can also numerically compute multiplier effects in our model, to measure the impact of government or of autonomous investment shocks on output in the current and

\footnotetext{
${ }^{7}$ The endogenous propagation mechanism of the model does not depend on parameters involving the exogenous shock processes, and is not sensitive to the values of $\frac{\Delta}{c}$ and $\frac{g}{y}$.

${ }^{8}$ The degree of markup or externality required for indeterminacy can be reduced even further if the time discount factor $\beta$ is larger or if the steady-state depreciation rate $\delta$ is higher. For example, when $\beta=0.995$, the minimum value of $\eta$ for indeterminacy reduces to 0.057 and complex eigenvalues arise for $\eta=0.058$. For analytical conditions of indeterminacy linking $\eta$ to other structural parameters, see Wen (1998).

${ }^{9}$ See Benhabib and Farmer (1994) and Farmer and Guo (1994). In our model, the slope of the aggregate labor demand curve $($ in $\log )$ is given by $(1-\alpha)(1+\eta)-1$. A negative slope requires $\eta<\frac{\alpha}{1-\alpha}=0.43$, when $\alpha=0.3$.

${ }^{10}$ See Wen (1998) for details.
} 
subsequent periods. For example, with the present calibrations, and assuming that the government shocks follow a stationary $A R(1)$ process with persistence coefficient of 0.9 , at the maximum impact point the government-spending multiplier is 1.84 . In contrast, in a standard RBC model, the government-spending multiplier is 0.14 (e.g., KPR, 1988). While the dynamics of indeteterminacy around the steady state translate the initial impact of the shocks into persistent, serially correlated movements in capital and investment, the propagation mechanism depends on the multiplier effects of these state variables on output. If changes in the state variables have little effect on output, then the initial impact of a shock would be quickly damped, even if the state variables are highly serially correlated. This is exactly what happens in standard RBC models where the capital stock is highly serially correlated but output growth is not, because changes in the capital stock have very little multiplier effect on output (e.g., see the analyses of Wen, 1995).

\section{Simple Measure of Comovement}

This section presents a preliminary evaluation of our model based on a small set of unconditional second moments commonly used in the literature for evaluating the empirical success of RBC models. The model's second moments depend on the variance of the sunspot variable, $v_{s t}$, hence we use $\sigma_{s}^{2}$ as an equilibrium selection device in our simulations. In particular, in the cases when only fundamental shocks are considered, the variance of sunspots is set to zero.

We calibrate parameters pertaining to exogenous shocks following the existing literature. Specifically, we assume through out the paper that shocks to fundamentals follow stationary $A R(1)$ processes and the sunspot shocks are i.i.d.:

$$
\begin{aligned}
\log \Delta_{t} & =\rho_{\Delta} \log \Delta_{t-1}+\varepsilon_{\Delta t}, \varepsilon_{\Delta t} \sim i . i . d\left(0, \sigma_{\Delta}^{2}\right) \\
\log g_{t} & =\rho_{g} \log g_{t}+\varepsilon_{g t}, \varepsilon_{g t} \sim i . i . d\left(0, \sigma_{g}^{2}\right) \\
v_{s t} & =\varepsilon_{s t}, \varepsilon_{s t} \sim i . i . d\left(0, \sigma_{s}^{2}\right)
\end{aligned}
$$

where innovations in fundamental shocks are orthogonal to each other and are orthogonal to sunspots, $v_{s t}$. We choose $\rho_{g}=\rho_{\Delta}=0.9{ }^{11}$ Since only the relative moments matter in our discussions, we do not calibrate the variances of the different shocks in the present section and we arbitrarily set $\sigma_{g}=\sigma_{\Delta}=\sigma_{s}=1$.

The predicted second moments for growth rates and their empirical counter parts are reported in table 1. For comparison purpose, predictions from a standard RBC model of

\footnotetext{
${ }^{11}$ Given the stationarity assumption, the more persistent the shocks are, the better our model explains the U.S. data. The estimated $\rho_{g}$ for the detrended U.S. real government expenditure (1960:1 - 1994:4) is 0.98, and the estimated $\rho_{\Delta}$ from the intertemporal Euler equation of consumption by Baxter and King (1991) is 0.97. Using these larger persistence parameter values for $\rho_{g}$ and $\rho_{\Delta}$ in our model provides better matches between our model and the U.S. data with respect to all the business cycle facts considered in this paper. We choose to use the more conservative values of 0.9 simply to show that our model is robust to the values of the persistence parameters as long as they are large enough to capture the notion that demand shocks are highly persistent. For calibration exercises using larger values of $\rho_{g}$ and $\rho_{\Delta}$, see our working paper (Benhabib and Wen, 2000).
} 
King, Plosser, and Rebelo (KPR, 1988) driven by permanent technology shocks are also reported in table 1 . The same parameter values are used for the KPR model for any shared common parameters.

Table 1. Selective Moments for Growth Rates

\begin{tabular}{|c|c|c|c|c|c|c|c|c|c|c|c|}
\hline & \multicolumn{3}{|c|}{$\overline{\sigma_{\Delta x} / \sigma_{\Delta y}}$} & \multicolumn{4}{|c|}{$\bar{c} \operatorname{cor}\left(\Delta x_{t}, \Delta y_{t}\right)$} & \multicolumn{4}{|c|}{$\overline{c o r}\left(\Delta x_{t}, \Delta x_{t-1}\right)$} \\
\hline & $\Delta c$ & $\Delta i$ & $\Delta n$ & $\overline{\Delta c}$ & $\Delta i$ & $\Delta n$ & $\Delta p$ & $\overline{\Delta y}$ & $\Delta c$ & $\overline{\Delta i}$ & $\overline{\Delta n}$ \\
\hline U.S. & 0.62 & 3.15 & 1.09 & 0.76 & 0.80 & 0.43 & 0.48 & 0.41 & 0.37 & 0.51 & 0.11 \\
\hline $\mathrm{KPR}_{A}$ & 0.52 & 2.83 & 0.50 & 0.98 & 0.99 & 0.98 & 0.98 & -0.005 & 0.09 & -0.03 & -0.04 \\
\hline $\mathrm{ICM}_{\Delta}$ & 0.50 & 4.90 & 0.99 & -0.02 & 0.96 & 0.99 & 0.38 & 0.78 & -0.05 & 0.56 & 0.78 \\
\hline $\mathrm{ICM}_{g}$ & 0.03 & 4.90 & 0.99 & 0.38 & 0.96 & 0.99 & 0.38 & 0.78 & 0.94 & 0.56 & 0.78 \\
\hline $\mathrm{ICM}_{s}$ & 0.02 & 4.65 & 0.99 & 0.62 & 1.00 & 0.99 & 0.61 & 0.10 & 0.59 & 0.10 & 0.10 \\
\hline
\end{tabular}

The estimated US sample moments can vary depending on the precise definition of the variables in question and the sample period used. ${ }^{12}$ However, regardless of the definitions of variables, the most robust features of the US data (regarded as the defining features of the US business cycle in the literature) are: (1) Consumption growth is less volatile than output growth, which in turn is less volatile than investment growth, and employment growth is about as volatile as output growth (top row first column in table 1). ${ }^{13}$ (2) Changes in consumption, investment, employment, and productivity are all positively correlated with changes in output (top row second column). (3) The growth rates of output, consumption, investment, and hours are all positively serially correlated (top row third column).

The middle row of table 1 confirms that the standard RBC model is quite successful in matching the relative volatilities of consumption and investment growth with respect to output growth as well as the positive comovements between changes in consumption, investment, employment, productivity and changes in output (second row). But, the model fails dramatically on an important ground: the serial correlations in growth rate are essentially zero for output, consumption, investment, and hours (second row, third column). This failure has provided the ground for criticisms of RBC models by Cogley and Nason (1995) and Rotemberg and Woodford (1996). In addition, the KPR model generates employment growth that is too smooth relative to output growth $\left(\sigma_{\Delta n} / \sigma_{\Delta y}\right.$ is 0.5 in the KPR model and it is 1.09 in the U.S. economy), and it generates a correlation between productivity and output growth that is too high $(\operatorname{cor}(\Delta p, \Delta y)$ is 0.98 in the KPR model and it is 0.48 in the U.S. economy).

The bottom rows in table 1 presents predictions of the indeterminate capacity utilization model (ICM) driven by the three types of demand shocks respectively. It shows that all

\footnotetext{
${ }^{12}$ The data used here are logged aggregate quarterly U.S. real GDP, real fixed investment, real consumption on nondurable goods and services, and total weekly hours from household survey. All data series are from CITIBASE (1960:1 - 1994:4). Productivity is defined as labor to output ratio.

${ }^{13}$ Also see Kydland and Prescott (1982) and Prescott (1986) on discussions regarding these statistics.
} 
three versions of the model are comparable comfortably to the standard RBC model driven by technology shocks with regard to predictions on the relative volatility orders with respect to output growth (first column) and on the comovements of growth rates (second column). There are however a couple of exceptions. First, when the shocks are from consumption demand $\left(\mathrm{ICM}_{\Delta}\right)$, the correlation between consumption growth and output growth is slightly negative. Second, under government spending shocks or sunspots shocks $\left(\mathrm{ICM}_{g}\right.$ and $\left.\mathrm{ICM}_{s}\right)$ the relative volatility of consumption growth is too small. However, the indeterminate model is quite successful in predicting the volatility of employment growth relative to output growth $\left(\sigma_{\Delta n} / \sigma_{\Delta y}\right.$ is 0.99$)$ and the correlations between productivity growth and output growth $(\operatorname{cor}(\Delta p, \Delta y)$ is positive but substantially less than one). Most importantly, all versions of the model are capable of predicting the positive serial correlations in the growth rates of output, investment, and hours (third column). Overall, therefore, with regard to the conventional measures of business cycles, it is fair to say that the indeterminate RBC model driven solely by demand shocks does no worse than the standard RBC model driven by technology shocks.

\section{Hump-Shaped Output Dynamics}

Cogley and Nason (1995) point out that standard RBC models cannot explain two related stylized fact about US output: its impulse responses to transitory demand shocks are humpshaped and it exhibits substantial amount of serial correlation in growth rate. This section formally tests the capacity utilization model of indeterminacy in light of these criticisms.

\subsection{Stylized Responses to Demand}

Following Blanchard and Quah (1989) and Cogley and Nason (1995), we decompose U.S. aggregate output into two components, one pertaining to permanent shocks and the other pertaining to transitory shocks. ${ }^{14}$ The transitory component is interpreted by Blanchard and Quah as fluctuations due to aggregate demand shocks. We use the ratio of investment to output as the covariate in a bivariate VAR to carry out the Blanchard -Quah decomposition. Balanced growth in RBC models implies that the investment to output ratio is stationary. The demand shocks so identified have the natural interpretation of being disturbances that affect short-run aggregate savings, such as shocks to government spending, to consumers' preferences, or to firms' autonomous investment. ${ }^{15}$

\footnotetext{
${ }^{14}$ Output is defined here as the sum of U.S. real fixed investment, total real consumption, and real government expenditure. All data series are from CITIBASE (1960:1 - 1994:4). 2 lags are used in the VAR estimation and they capture the dynamics of the data quite well. More lags tend to produce coefficients with large standard errors. A linear time trend is included in the VARs to capture any possible time trends. Although the definition of output is slightly different from that used for producing table 1 , the fundamental features of the data are well preserved. The current definition of output is more consistent with the theoretical counterpart of the models studied in the paper.

${ }^{15}$ Cochrane (1994) uses consumption to output ratio as the covariate. Cogley and Nason (1995) use per capita hours as the covariate. We choose the investment to output ratio as the covariate also because it appears to be more stationary than the series of consumption to output ratio and the series of per capita
} 
Figure 1 shows impulse responses to demand from output (window A1) and investment (window B1) as well as the implied autocorrelation functions for output growth (window B1) and investment growth (window B2). The impulse responses exhibit the familiar humpshaped, trend-reverting dynamics. These dynamics are very similar to those identified by Blanchard and Quah (1989). ${ }^{16}$ The implied autocorrelation functions for growth rate (second row) also show the familiar pattern with positive serial correlations for the first couple of lags and negative serial correlations afterwards. To ensure that the output dynamics presented in Figure 1 reflect responses to demand disturbances, we also used the government expenditure to GDP ratio as the covariate in carrying out the Blanchard-Quah decomposition. The identified output responses using the government expenditure to GDP ratio turned out to be very similar to those identified using the investment to output ratio.

As pointed out by Cogley and Nason, a fundamental weakness of the real-business-cycle paradigm as a convincing explanation of the business cycle is its failure to account for the above salient business cycle dynamics. Under transitory technology shocks, standard RBC models generate monotonic impulse responses for output and near-zero serial correlations for output growth. This is illustrated in figure $2 .{ }^{17}$

\subsection{Predicted Responses to Demand}

We first examine the predictions of our model under a single type of demand shock. We then examine the model's predictions under different combinations of more than one type of demand shocks. We test each of these versions of the model using a version of the $Q$-test proposed by Cogley and Nason (1995) by computing the generalized $Q$ statistics, which are defined as:

$$
Q=(\hat{c}-c)^{\prime} \hat{V}_{c}^{-1}(\hat{c}-c) .
$$

The vector $\hat{c}$ represents the sample impulse response function of GDP or autocorrelation function of GDP growth implied by the US data, and $c$ represents the mean of $N(=500)$ estimated impulse response functions or autocorrelation functions implied by the simulated time series of the model (the sample length of each simulation is the same as that of the U.S. data, namely, 140 quarters). ${ }^{18}$ That is, $c=\frac{1}{N} \sum_{i=1}^{N} c_{i}$. The covariance matrix, $\hat{V}_{c}$, is

working hours for post-war US economy. The conditional impulse responses identified are nevertheless qualitatively very similar.

${ }^{16}$ Similar hump-shaped impulse responses are also observed in other variables such as hours. We focus on output dynamics in the present section, however. See our working paper (Benhabib and Wen, 2000) for analysis on dynamics of investment and hours.

${ }^{17}$ Figure 2 shows the impulse responses of output and the implied autocorrelation function of output growth in the King-Plosser-Rebelo (1988) model under transitory $A R(1)$ technology shocks with the autocorrelation coefficient of 0.9 . The results for output are similar when transitory $A R(1)$ demand shocks are used. But it is well known that standard RBC models driven by transitory demand shocks generate counter-factual predictions regarding the comovements of consumption, investment, hours and output (see Baxter and King, 1991).

${ }^{18}$ The variance of the sunspots acts as the equilibrium selection device. Namely, in each simulation under fundamental shocks, both the level and the variance of the sunspot variable, $v_{s}$, are set to zero. Since all shocks in the model are assumed to be orthogonal and transitory, we do not use the Blanchard- 
estimated by

$$
\hat{V}_{c}=\frac{1}{N} \sum_{i=1}^{N}\left(c_{i}-c\right)\left(c_{i}-c\right)^{\prime} .
$$

The test statistic $Q$ has approximate $\chi^{2}$ distribution with degrees of freedom equal to the number of elements (lags) in $c$. Following Cogley and Nason, the number of lags chosen is 8 , which gives a critical value of 20.1 at the $1 \%$ significance level and a critical value of 15.5 at the $5 \%$ significance level.

In order to highlight the dramatic effect of indeterminacy on the propagation mechanism, in figure 3 we present impulse responses of the model to demand shocks when $\eta=0.1$ and the steady state is locally a saddle. Figure 3 shows the responses of output, consumption, investment and hours to one standard deviation increase in $\varepsilon_{\Delta}$ (solid lines) and in $\varepsilon_{g}$ (dashed lines) respectively. In contrast, we present in figure 4 the impulse responses of the model for the case when $\eta=0.11$ and the steady state is a sink, where solid lines pertain to consumption shock $\left(\varepsilon_{\Delta}\right)$, long dashed lines to government shock $\left(\varepsilon_{g}\right)$, and short dashed lines to sunspot shock $\left(\varepsilon_{s}\right) .{ }^{19}$

By comparison, several features of figures 3 and 4 deserve particular mention. First, capacity utilization can induce positive comovements in the model under each type of demand shock even when the model is locally determinate (figure 3). This is in stark contrast with standard RBC models with fixed capacity utilization, where an extremely high degree of externality is necessary to generate positive comovements among consumption, investment, hours and output under consumption demand shocks (e.g., see Baxter and King, 1991). Second, government spending can be fully expansionary, generating positive comovements for all variables considered regardless of indeterminacy, indicating that the multiplier effect is not the consequence of indeterminacy. Third, without indeterminacy, the impulse responses of output to demand shocks are monotonic, as opposed to hump-shaped, despite the presence of capacity utilization. Fourth, the initial impulse responses of output and other variables become hump-shaped under indeterminacy only when demand shocks are serially correlated (figure 4), indicating that continuous expansion of output and accelerated economic growth are possible in response to demand shocks only if the increases in aggregate demand are expected to last for more than one period (e.g., the responses to i.i.d. sunspot shocks - long dashed lines - do not exhibit the initial hump). ${ }^{20}$

Next, we test the likelihood that the transitory component in U.S. GDP is generated by demand shocks in an indeterminate economy like ours. The $Q$ statistics for impulse response functions of output and autocorrelation functions of output growth are reported in table 2 (second and third column respectively). The benchmark versions of the model

Quah decomposition to estimate conditional impulse response functions with respect to transitory shocks for the simulated series. Instead, a univariate VAR suffices. We use a lag length of four in the univariate VAR estimation. Using other number of lags produces little difference in the results. The autocorrelation functions for growth rates are estimated using the definition, $E\left(x_{t}-\bar{y}\right)\left(x_{t-\tau}-\bar{y}\right)$, for $\tau \geq 0$.

${ }^{19}$ The impulse responses in figure 4 are the means of 500 sample estimates based on simulated time series.

${ }^{20}$ The fact that sunspots cannot generate hump-shaped impulse responses for output was pointed out by Schmitt-Grohe (2000). 
driven by a single type of demand shock are reported in the top panel (top 3 rows). They all perform poorly under the $Q$ test. This is so because the model tends to generate too much autocorrelation for output under serially correlated shocks and too little autocorrelation under i.i.d demand shocks. Therefore, the cyclical phase of output is either shifted either forward or backward with respect to the U.S. data (see figure 4). This suggests that mixed demand shocks can improve the model's goodness of fit. Versions of the model driven by a combination of serially correlated shocks and i.i.d. shocks are reported in the lower panel of table 2 (bottom 4 rows). ${ }^{21}$ They perform extremely well, especially with respect to the autocorrelation function of output growth. All versions with mixed demand shocks, for example, pass the $Q$ test at the $5 \%$ significance level. In the cases of autocorrelation functions of output growth, the significance level is generally around or above $95 \%$, implying that there is virtually no difference between the model generated data and the actual U.S. data. Figure 5 shows an example that under mixed demand shocks $\left(\Delta_{t}\right.$ and $\left.s_{t}\right)$ the impulse response function of output and autocorrelation function of output growth match the U.S. data quite well. ${ }^{22}$

Table 2. $Q$ Statistics

\begin{tabular}{c|cc}
\hline \hline Shocks & $Q_{i m p}$ & $Q_{a c f}$ \\
\hline$\Delta_{t}[A R(1)]$ & 166 & 90 \\
$g_{t}[A R(1)]$ & 270 & 101 \\
$s_{t}[i i d]$ & 451 & 43 \\
\hline$\Delta_{t}[A R(1)], s_{t}[i i d]$ & 12.8 & 1.9 \\
$g_{t}[A R(1)], s_{t}[i i d]$ & 14.2 & 1.8 \\
$\Delta_{t}[A R(1)], g_{t}[i i d]$ & 14.1 & 2.8 \\
$g_{t}[A R(1)], \Delta_{t}[i i d]$ & 13.5 & 2.3 \\
\hline
\end{tabular}

\section{The Forecastable-Movement Puzzle}

Rotemberg and Woodford (1996) highlight an essential characteristic of economic fluctuations that is also difficult for the canonical real-business-cycle paradigm to explain. They show that expected changes in US output, hours, investment and consumption have striking patterns: 1) They are highly forecastable in the sense that the standard deviations of

\footnotetext{
${ }^{21}$ In the cases where more than one type of shocks are active, the relative stdandard deviations of these shocks are chosen so that the mangnitudes of initial impulse responses best match the data.

${ }^{22}$ We also investigated cases where sunspots are correlated (either positively or negatively) with innovations in fundamental shocks. The results indicate that correlations among different types of demand shocks do not affect the model's goodness of fit, as long as the relative standard deviations of different shocks can be adjusted accordingly. In addition, we have tested the predictions of the model with respect to other variables such as investment and hours. The results are also very good with regard to the autocorrelation functions of growth rates, but impulse response functions do not perform as well as that of output. The model's goodness of fit can be further improved if we allow the persistence parameter of fundamental shocks to be estimated rather than calibrated and fixed at 0.9. See our working paper (Benhabib and Wen, 2000) for these results.
} 
expected changes in these variables are about half as large as the standard deviations of actual changes in these variables; 2) they are strongly positively correlated with each other; 3 ) the relative volatilities of expected changes follow a order similar to the relative volatilities of actual changes, namely, in response to one percent increase in expected-output growth, the expected-consumption growth is substantially less than one percent and the expectedinvestment growth is substantially greater than one percent. Standard RBC models driven by permanent technology shocks are not able to predict these regularities. The theoretical counter parts in these models have very little forecastability, they are negatively correlated, and they follow an entirely different pattern of volatility orders from that of actual changes.

Table 3 presents estimated and predicted ratios of standard deviations between expected and actual $k$-quarter changes in output. ${ }^{23}$ The first row shows that in post-war U.S. economy, changes in output are highly forecastable (numbers in parentheses are estimates reported by Rotemberg and Woodford (1996) using different data samples). Our data sample indicates that at least 36 percent of actual changes in output or more are forecastable, whereas Rotemberg and Woodford report that more than 55 percent of actual changes in output are forecastable. The second row, in contrast, shows that changes in output in the KPR model driven by permanent technology shocks have essentially zero forecastability. This is so because changes in output are essentially white noise processes in standard RBC models (e.g., see Wen (1995) for analytical analysis). The lower three rows in table 3, however, show that the indeterminate capacity utilization model predicts that changes in output are highly forecastable, and more so than what is observed in the U.S. data. The best match is delivered by sunspot shocks (last row). The extremely high forecastability is attributable to the strongly periodic propagation mechanism of the model. ${ }^{24}$

\footnotetext{
${ }^{23}$ The variables used in the VARs for computing the forecastable moments in the U.S. economy are $\left\{\Delta y_{t}, i_{t}-y_{t}, h_{t}\right\}$, where aggregate output $y$ and investment $i$ are defined in the same way as in the previous section, and where hours $h$ are defined as detrended aggregate total average weekly hours by household survey data. The forecastable moments are computed in the same way as that in Rotemberg and Woodford (1996). We used investment to output ratio rather than consumption to output ratio in the VARs so as to be consistent with the VARs used in the previous section. The results are nevertheless very similar to those obtained by Rotemberg and Woodford (1996). The predicted moments for forecastable changes in theoretical models are computed based on linearized equilibrium decision rules derived from the models.

${ }^{24}$ Schmitt-Grohe (2000) showed that sunspot shocks can account for the estimated forecastability of changes in output, but did not examine other types of demand shocks. Notice that consumption demand shocks and government spending shocks give exactly the same predictions in table 4 .
} 
Table 3. Relative Standard Deviations of Cumulative Changes in Output

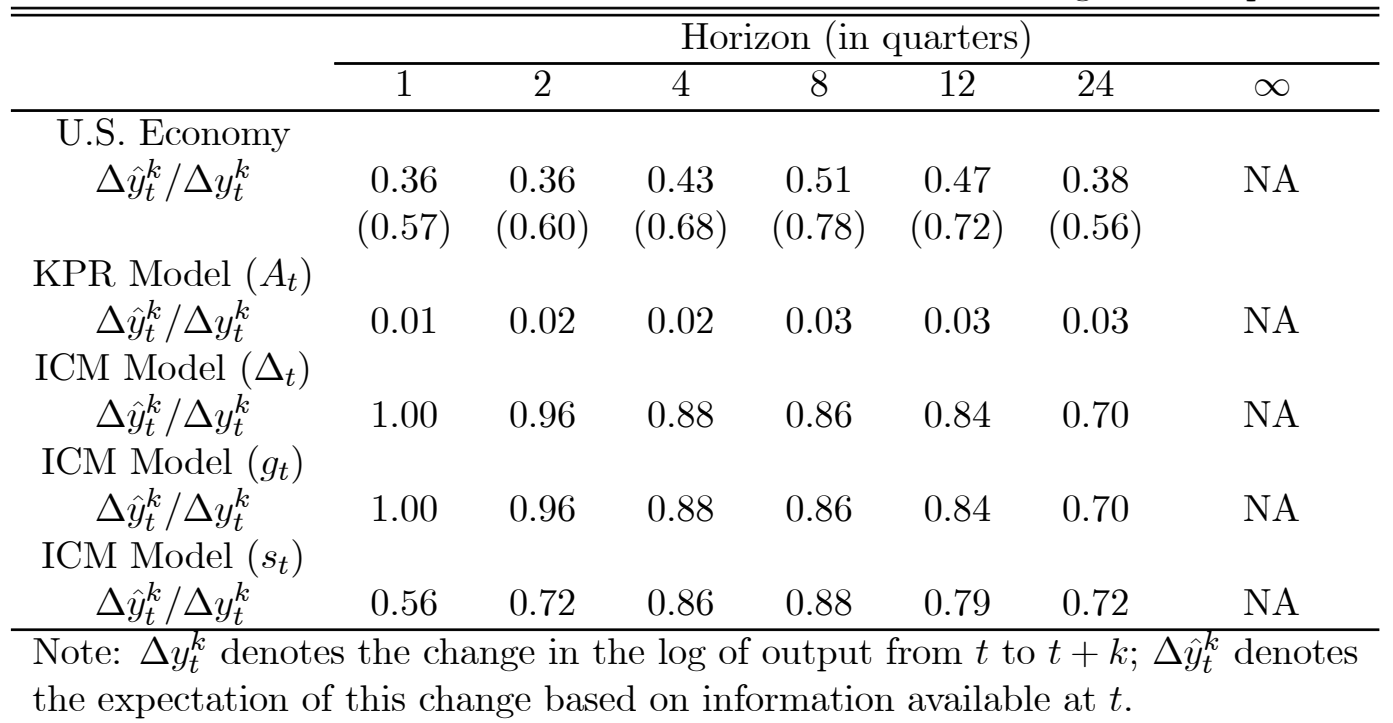

Rotemberg and Woodford's (1996) main criticism of the real business cycle theory, however, is that it implies counterfactual comovements and counterfactual relative volatilities among forecastable changes in hours, consumption, investment, and output. Table 4 presents estimates and model predictions for the correlation between expected $k$ quarter changes in output and corresponding $k$-quarter changes in consumption, hours, and investment. ${ }^{25}$ The top panel of table 4 shows that expected changes in hours and investment are highly positively correlated with expected changes in output for all forecasting horizons considered, while expected changes in consumption are positively correlated with that of output but substantially less so than hours and investment. The predictions of the KPR model are shown in the middle panel. It correctly predicts the highly positive correlations with respect to hours and investment series, but it fails dramatically on consumption. It generates perfectly negative correlations between expected changes in consumption and output. ${ }^{26}$

The lower panels of table 4 presents predictions of the indeterminate model under each type of demand shocks respectively. It performs much better than the KPR model in all

\footnotetext{
${ }^{25}$ Following Rotemberg and Woodford (1996), we use the equation,

$$
0.74 \hat{c}_{t}+0.26 \hat{\imath}_{t}=\hat{y}_{t},
$$

to compute moments pertaining to consumption. Adding a government spending component into the equation does not change the results substantially.

${ }^{26}$ Rotemberg and Woodford (1996) found that the sign of predicted correlations in the KPR model depends sensitively on the parameters. For example, the correlation between expected-consumption growth and expected-output growth can be positive if the intertemporal elasticity of substitution parameter in the preference or the capital-output elasticity in the technology change. But the consequence is that the correlations of other variables (investment or hours) change sign from positive to negative. It is therefore not possible to generate positive correlations with output for all variables simultaneously with any sensible parameter choices in the KPR model.
} 
aspects. The improvement on the correlation between expected changes in consumption and output, for example, is particularly obvious and substantial regardless the source of demand shocks or the forecasting horizon considered. Namely, expected changes in consumption are predicted to be positively correlated with that of output for all horizons considered and the correlations are substantially less than one (the only exception is the first quarter change under consumption shocks). ${ }^{27}$

Table 4. Correlations among Forecasted Changes

\begin{tabular}{|c|c|c|c|c|c|c|c|c|}
\hline \multicolumn{2}{|c|}{ "Horizon (in quarters) } & 1 & 2 & 4 & 8 & 12 & 24 & $\infty$ \\
\hline \multicolumn{9}{|c|}{ U.S. Economy } \\
\hline \multicolumn{2}{|c|}{$\operatorname{Cor}\left(\Delta \hat{c}_{t}^{k}, \Delta \hat{y}_{t}^{k}\right)$} & 0.336 & 0.388 & 0.335 & 0.324 & 0.392 & 0.488 & 0.498 \\
\hline \multicolumn{2}{|c|}{$\operatorname{Cor}\left(\Delta \hat{n}_{t}^{k}, \Delta \hat{y}_{t}^{k}\right)$} & 0.884 & 0.933 & 0.952 & 0.968 & 0.972 & 0.967 & 0.965 \\
\hline \multicolumn{2}{|c|}{$\operatorname{Cor}\left(\Delta \hat{\imath}_{t}^{k}, \Delta \hat{y}_{t}^{k}\right)$} & 0.895 & 0.924 & 0.937 & 0.932 & 0.912 & 0.842 & 0.825 \\
\hline \multicolumn{9}{|c|}{$\operatorname{KPR}$ Model $\left(A_{t}\right)$} \\
\hline \multicolumn{2}{|c|}{$\operatorname{Cor}\left(\Delta \hat{c}_{t}^{k}, \Delta \hat{y}_{t}^{k}\right)$} & -1.00 & -1.00 & -1.00 & -1.00 & -1.00 & -1.00 & -1.00 \\
\hline \multicolumn{2}{|c|}{$\operatorname{Cor}\left(\Delta \hat{n}_{t}^{k}, \Delta \hat{y}_{t}^{k}\right)$} & 1.00 & 1.00 & 1.00 & 1.00 & 1.00 & 1.00 & 1.00 \\
\hline \multicolumn{2}{|c|}{$\operatorname{Cor}\left(\Delta \hat{\imath}_{t}^{k}, \Delta \hat{y}_{t}^{k}\right)$} & 1.00 & 1.00 & 1.00 & 1.00 & 1.00 & 1.00 & 1.00 \\
\hline \multicolumn{9}{|c|}{ ICM Model $\left(\Delta_{t}, g_{t}, s_{t}\right)$} \\
\hline \multirow{3}{*}{$\left(\Delta_{t}\right)$} & $\operatorname{Cor}\left(\Delta \hat{c}_{t}^{k}, \Delta \hat{y}_{t}^{k}\right)$ & -0.094 & 0.029 & 0.265 & 0.557 & 0.627 & 0.526 & 0.561 \\
\hline & $\operatorname{Cor}\left(\Delta \hat{n}_{t}^{k}, \Delta \hat{y}_{t}^{k}\right)$ & 0.9996 & 0.9995 & 0.9994 & 0.9994 & 0.9994 & 0.9990 & 0.9989 \\
\hline & $\operatorname{Cor}\left(\Delta \hat{\imath}_{t}^{k}, \Delta \hat{y}_{t}^{k}\right)$ & 0.998 & 0.998 & 0.997 & 0.997 & 0.994 & 0.976 & 0.974 \\
\hline \multirow{3}{*}{$\left(g_{t}\right)$} & $\operatorname{Cor}\left(\Delta \hat{c}_{t}^{k}, \Delta \hat{y}_{t}^{k}\right)$ & 0.381 & 0.372 & 0.306 & 0.199 & 0.296 & 0.434 & 0.408 \\
\hline & $\operatorname{Cor}\left(\Delta \hat{n}_{t}^{k}, \Delta \hat{y}_{t}^{k}\right)$ & 0.9996 & 0.9995 & 0.9994 & 0.9994 & 0.9994 & 0.9990 & 0.9989 \\
\hline & $\operatorname{Cor}\left(\Delta \hat{\imath}_{t}^{k}, \Delta \hat{y}_{t}^{k}\right)$ & 0.998 & 0.998 & 0.997 & 0.997 & 0.994 & 0.978 & 0.974 \\
\hline \multirow{3}{*}{$\left(s_{t}\right)$} & $\operatorname{Cor}\left(\Delta \hat{c}_{t}^{k}, \Delta \hat{y}_{t}^{k}\right)$ & 0.033 & 0.117 & 0.267 & 0.385 & 0.328 & 0.383 & 0.370 \\
\hline & $\operatorname{Cor}\left(\Delta \hat{n}_{t}^{k}, \Delta \hat{y}_{t}^{k}\right)$ & 0.9997 & 0.9997 & 0.9997 & 0.9995 & 0.9993 & 0.9995 & 0.9994 \\
\hline & $\operatorname{Cor}\left(\Delta \hat{i}_{t}^{k}, \Delta \hat{y}_{t}^{k}\right)$ & 0.9999 & 0.9999 & 0.9999 & 0.9999 & 0.9998 & 0.9999 & 0.9998 \\
\hline
\end{tabular}

Note: $\Delta \hat{x}_{t}^{k}$ denotes the expected change in $x_{t}$ from $t$ to $t+k$ based on information available at $t$.

Table 5 presents regression coefficients of the expected changes in consumption, hours, and investment on expected changes in output. As pointed out by Rotemberg and Woodford

\footnotetext{
${ }^{27}$ As before, consumption demand shocks $\left(\Delta_{t}\right)$ and government spending shocks $\left(g_{t}\right)$ generate exactly the same predictions for investment and hours. In the short horizon, government spending shocks and sunspot shocks preform better than consumption demand shocks with respect to consumption series. It is clear from table 5 that all three versions of the model outperform the KPR model significantly with respect to all variables and all forecasting horizons considered. This is in sharp contrast with the analysis of Schmitt-Grohe (2000). Using a two-sector indeterminate model with fixed capacity utilization, Schimitt-Grohe shows that sunspots shocks predict strongly negative correlations between expected-consumption growth and expectedoutput growth. Hence, she concludes that indeterminate RBC models driven solely by sunspots do not overcome the shortcomings of standard RBC models in this regard. Our results indicate that this is not true for our model.
} 
(1996), the regression coefficients are good measures of the relative volatilities of the various series, and they provide an economic way of discussing the movement of these variables over the business cycle. For example, they indicate the percentage by which a given variable can be expected to change when output is expected to increase by one percent. Table 5 shows that the elasticity (regression coefficient) of expected-consumption growth with respect to expected-output growth is positive but substantially less than one, while the corresponding elasticity of expected-investment growth is substantially greater than one for all forecasting horizons. This means that expected changes in consumption are very smooth while expected changes in investment are very volatile in response to expected changes in output. Expected-hours growth, on the other hand, responds nearly one for one to expected changes in output in the U.S. economy.

These salient features of the data are not captured by the KPR model. The middle panel in table 5 shows that the elasticity of expected-consumption growth with respect to expected-output growth is negative and substantially larger than one in absolute value. This leads to excessively volatile expected-investment growth (in the order of nearly 30!) in response to one percent expected changes in output. Such excessive volatility in expected growth is also observed in hours (the elasticity is nearly 8 !).

The lower panels in table 5, in contrast, show a remarkable improvement on the KPR model in explaining the elasticities of forecastable changes in consumption, hours, and investment with respect to forecastable changes in output. The magnitudes of regression coefficients for each series considered under each type of demand shock are broadly consistent with the data for the indeterminate model. For example, for each type of demand shock and for most forecasting horizons, the elasticity of expected-consumption growth with respect to expected-output growth is positive and substantially less than one, while the expected growth of hours responds nearly one for one to expected-output growth. Quantitatively however, the indeterminate model tends to underestimate the elasticity of expectedconsumption growth and overestimate the expected-investment growth. ${ }^{28}$

\footnotetext{
${ }^{28}$ Note that the effects of consumption demand shocks and government spending shocks on the dynamics of hours and investment are still exactly the same as before. But consumption shocks appear to give much better predictions than the other types of demand shocks regarding consumption elasticities as the forecasting horizon increases.
} 
Table 5. Regression Coefficients among Forecasted Changes

\begin{tabular}{|c|c|c|c|c|c|c|c|}
\hline "Horizon (in quarters) & $\overline{1} 1$ & 2 & $\overline{4}$ & 8 & $\overline{12}$ & 24 & $\infty$ \\
\hline \multicolumn{8}{|l|}{ U.S. Economy } \\
\hline$\Delta \hat{c}_{t}^{k}$ on $\Delta \hat{y}_{t}^{k}$ & 0.204 & 0.200 & 0.159 & 0.159 & 0.217 & 0.356 & 0.382 \\
\hline$\Delta \hat{n}_{t}^{k}$ on $\Delta \hat{y}_{t}^{k}$ & 0.896 & 0.895 & 0.874 & 0.880 & 0.902 & 0.933 & 0.937 \\
\hline$\Delta \hat{\imath}_{t}^{k}$ on $\Delta \hat{y}_{t}^{k}$ & 3.266 & 3.277 & 3.395 & 3.393 & 3.230 & 2.832 & 2.760 \\
\hline \multicolumn{8}{|l|}{$\operatorname{KPR}$ Model $\left(A_{t}\right)$} \\
\hline$\Delta \hat{c}_{t}^{k}$ on $\Delta \hat{y}_{t}^{k}$ & -6.770 & -6.770 & -6.770 & -6.770 & -6.770 & -6.770 & -6.770 \\
\hline$\Delta \hat{n}_{t}^{k}$ on $\Delta \hat{y}_{t}^{k}$ & 7.770 & 7.770 & 7.770 & 7.770 & 7.770 & 7.770 & 7.770 \\
\hline$\Delta \hat{\imath}_{t}^{k}$ on $\Delta \hat{y}_{t}^{k}$ & 29.595 & 29.595 & 29.595 & 29.595 & 29.595 & 29.595 & 29.595 \\
\hline \multicolumn{8}{|l|}{ ICM Model } \\
\hline$\Delta \hat{c}_{t}^{k}$ on $\Delta \hat{y}_{t}^{k}$ & -0.010 & 0.003 & 0.033 & 0.088 & 0.136 & 0.207 & 0.234 \\
\hline \begin{tabular}{l|l}
$\left(\Delta_{t}\right)$ & $\Delta \hat{n}_{t}^{k}$ on $\Delta \hat{y}_{t}^{k}$
\end{tabular} & 0.989 & 0.988 & 0.989 & 0.993 & 0.989 & 0.979 & 0.977 \\
\hline$\Delta \hat{\imath}_{t}^{k}$ on $\Delta \hat{y}_{t}^{k}$ & 4.707 & 4.671 & 4.598 & 4.439 & 4.308 & 4.112 & 4.039 \\
\hline$\Delta \hat{c}_{t}^{k}$ on $\Delta \hat{y}_{t}^{k}$ & 0.010 & 0.011 & 0.010 & 0.007 & 0.010 & 0.019 & 0.020 \\
\hline$\Delta \hat{n}_{t}^{k}$ on $\Delta \hat{y}_{t}^{k}$ & 0.989 & 0.988 & 0.989 & 0.993 & 0.989 & 0.979 & 0.977 \\
\hline$\Delta \hat{\imath}_{t}^{k}$ on $\Delta \hat{y}_{t}^{k}$ & 4.707 & 4.671 & 4.598 & 4.439 & 4.308 & 4.112 & 4.039 \\
\hline$\Delta \hat{c}_{t}^{k}$ on $\Delta \hat{y}_{t}^{k}$ & 0.001 & 0.003 & 0.006 & 0.011 & 0.012 & 0.012 & 0.012 \\
\hline$\Delta \hat{n}_{t}^{k}$ on $\Delta \hat{y}_{t}^{k}$ & 0.999 & 0.997 & 0.993 & 0.987 & 0.987 & 0.987 & 0.987 \\
\hline$\Delta \hat{\imath}_{t}^{k}$ on $\Delta \hat{y}_{t}^{k}$ & 4.678 & 4.673 & 4.663 & 4.649 & 4.648 & 4.648 & 4.647 \\
\hline
\end{tabular}

Note: $\Delta \hat{x}_{t}^{k}$ denotes the expected change in $x_{t}$ from $t$ to $t+k$ based on information available at $t$.

Caveat: Much applied work in the RBC literature assumes that technology shocks have a transitory component (e.g., see Kydland and Prescott (1982), Long and Plosser (1983), and King, Plosser, and Rebelo (1988)). This is so because it appears that in many aspects transitory technology shocks perform better than permanent technology shocks in explaining the U.S. data. Therefore, the Rotemberg-Woodford criticism of RBC models may apply only to the case of permanent technology shocks. Indeed, incorporating transitory technology shocks into the KPR model can substantially improve the model's performance regarding forecasted dynamics of the model. Table 6 shows that when technology follows a stationary $\mathrm{AR}(1)$ process, the model's performance in explaining the expected changes of various variables is substantially improved along all dimensions considered (the performance is now only slightly worse than that of the indeterminate model). For example, it does a pretty good job in accounting for the standard deviation of expected $k$-quarter changes relative to that of actual $k$-quarter changes. The correlation between expected-consumption growth and expected-output growth becomes much less negative and even turns positive for horizons beyond 4 quarters. The elasticities of expected changes in consumption, hours, and investment with respect to expected changes in output are also improved dramatically, especially for longer forecasting horizons (the bottom panel). However, transitory technology shocks do not help address the Cogley-Nason criticism (see Cogley and Nason, 1995). In addition, 
when the source of transitory shocks are from aggregate demand, the KPR model with permanent technology shocks performs just as poorly. This implies that our indeterminate RBC model still represents a significant progress over standard RBC models for explaining the business cycle. This is further illustrated by discussions in the next section, where we show that standard RBC models driven by technology shocks are not able to explain why consumption appears to lead output over the business cycle. Adding transitory technology shocks into these models only exacerbates the problem.

Table 6. Expected Changes under Transitory Technology Shocks (KPR)

\begin{tabular}{cccccccc}
\hline \hline & \multicolumn{7}{c}{ Horizon (in quarters) } \\
\cline { 2 - 8 } & 1 & 2 & 4 & 8 & 12 & 24 & $\infty$ \\
\hline Ratio of Standard Deviations & & & & & & & \\
$\Delta \hat{y}_{t}^{k} / \Delta y_{t}^{k}$ & 0.23 & 0.32 & 0.43 & 0.55 & 0.61 & 0.69 & $\mathrm{NA}$ \\
$\begin{array}{c}\text { Correlations with } \Delta \hat{y}_{t}^{k} \\
\Delta \hat{c}_{t}^{k}\end{array}$ & -0.391 & -0.315 & -0.158 & 0.132 & 0.348 & 0.693 & 0.778 \\
$\Delta \hat{n}_{t}^{k}$ & 0.980 & 0.978 & 0.975 & 0.968 & 0.959 & 0.927 & 0.855 \\
$\Delta \hat{\imath}_{t}^{k}$ & 0.987 & 0.986 & 0.984 & 0.980 & 0.975 & 0.959 & 0.925 \\
Regression Coeff. on $\Delta \hat{y}_{t}^{k}$ & & & & & & & \\
$\Delta \hat{c}_{t}^{k}$ & -0.095 & -0.076 & -0.038 & 0.034 & 0.099 & 0.251 & 0.429 \\
$\Delta \hat{n}_{t}^{k}$ & 1.095 & 1.076 & 1.038 & 0.966 & 0.901 & 0.749 & 0.571 \\
$\Delta \hat{\imath}_{t}^{k}$ & 5.029 & 4.958 & 4.819 & 4.556 & 4.316 & 3.755 & 3.103 \\
\hline
\end{tabular}

Note: $\Delta y_{t}^{k}$ denotes the change in the log of output from $t$ to $t+k ; \Delta \hat{y}_{t}^{k}$ denotes the the expectation of this change based on information available at $t$.

\section{Why does Consumption Lead the Business Cycle?}

Standard RBC models driven by technology shocks predict that consumption lags both output and investment. Post-war US data, however, reveal the opposite: at the business cycle frequency consumption leads output and investment. In what follows, we present the puzzle first, then we show that the puzzle can be resolved by our indeterminate RBC model.

\subsection{The Puzzle}

Applying the band-pass filter (Baxter and King, 1995) to post-war US data (1960:11994:4), we found that consumption leads output by one quarter and leads investment by two quarters at business cycle frequencies. The cross correlations among these series at these frequencies are reported in table 7 (top panel). It shows that the strongest correlation between consumption and output occurs at lags $k=-1$, whereas the strongest correlation between consumption and investment occurs at lags $k=-2$, indicating that consumption leads output and investment. ${ }^{29}$ Standard RBC models cannot explain these stylized facts. The middle panel in table 7 shows that the strongest correlation between consumption and

\footnotetext{
${ }^{29}$ The data used here are U.S. quarterly real GDP, real total consumption and real business fixed investment (total fixed investment minus residential investment) from 1960:1 to 1994:4. The same lead-lag
} 
output in the KPR model occurs at leads $k=+1$ and the strongest correlation between consumption and investment occurs at leads $k=+2$, indicating that consumption lags output and investment in the model. ${ }^{30}$

Table 7. Correlations at Business Cycle Frequencies (8-40 quarters)

\begin{tabular}{lccccccccc}
\hline \hline & $k=4$ & $k=3$ & $k=2$ & $k=1$ & $k=0$ & $k=-1$ & $k=-2$ & $k=-3$ & $k=-4$ \\
\cline { 2 - 9 } U.S. Sample & & & & & & & & & \\
Cor $\left(c_{t+k}, y_{t}\right)$ & -.020 & .248 & .519 & .749 & .899 & .929 & .853 & .688 & .468 \\
Cor $\left(c_{t+k}, i_{t}\right)$ & -.333 & -.128 & .119 & .374 & .600 & .746 & .805 & .770 & .652 \\
KPR Model & & & & & & & & & \\
Cor $\left(c_{t+k}, y_{t}\right)$ & .562 & .751 & .871 & .884 & .771 & .534 & .233 & -.073 & -.330 \\
& $(.114)$ & $(.070)$ & $(.034)$ & $(.025)$ & $(.021)$ & $(.020)$ & $(.049)$ & $(.081)$ & $(.101)$ \\
$\operatorname{Cor}\left(c_{t+k}, i_{t}\right)$ & .584 & .747 & .835 & .812 & .665 & .402 & .088 & -.218 & -.461 \\
& $(.109)$ & $(.066)$ & $(.041)$ & $(.040)$ & $(.036)$ & $(.023)$ & $(.039)$ & $(.067)$ & $(.082)$ \\
\hline
\end{tabular}

Note: Numbers in parentheses are standard errors based on 500 simulations.

The reasons for the sharp discrepancy between data and standard RBC models are simple. To highlight the problem at stake, we assume that technology shocks are transitory. The motive for consumption smoothing in a utility based optimization model implies that consumption comove with the capital stock (permanent income). At the same time, output and investment comove with transitory income. The capital stock, however, strongly lags investment because it is a weighted sum of past investment: ${ }^{31}$

$$
\begin{aligned}
k_{t} & =(1-\delta) k_{t-1}+i_{t-1} \\
& =i_{t-1}+(1-\delta) i_{t-2}+(1-\delta)^{2} i_{t-3}+\ldots
\end{aligned}
$$

Consequently, consumption (along with the capital stock) lags both output and investment in standard models.

relationship holds when output is defined as the sum of consumption, business fixed investment, and government expenditure. Housing investment is excluded for reasons that will become clear later. The window size used in the band-pass filter is for frequency interval of 8 to 40 quarters per cycle and we used 12 truncation points at each end of a time series. Changing the window size to "6 to 32 " quarters produces little difference in results.

${ }^{30}$ The predictions of theoretical models shown in tables 7 and 8 are based on 500 simulations, each with length of 140 quarters (the US sample size). We pass each series generated from each round of simulation through the band-pass filter to isolate the business cycle components, and then compute the cross correlations. The model predictions shown in tables 7 and 8 are the means and standard errors of cross correlations based on the 500 simulations. The predictions of the KPR model are generated under stationary AR(1) technology shocks with first-order autocorrelation coefficient of 0.9 . When technology shocks are permanent in the KPR model, consumption appears to lag investment by one quarter and coincide with output.

${ }^{31}$ The linear filter,

$$
f(L)=1+(1-\delta) L+(1-\delta)^{2} L^{2}+\ldots=\frac{1}{(1-(1-\delta) L)},
$$

is a backward phase shifter. E.g., see Harvey (1993, section 6.6) on the phase effect of linear filters. 
If the technology-shock view is correct, it is then puzzling to observe consumption leading the business cycle in data. It is tempting to think that sluggish investment adjustment may hold the key for explaining the puzzle. The idea is that if investment responds to technology shocks with a lag, it would then appear to lag output. This, however, does not necessarily result in consumption leading output. When investment is slow to respond to technology shocks, consumption would be forced to absorb the impact of technology shocks. Although this helps break the link between consumption and the capital stock at the impact period (namely, by preventing consumption from complete smoothing), it does not resolve the puzzle because consumption would then appear to coincide with output, rather than lead output..$^{32}$

An alternative explanation is that business cycles are caused mainly by consumption demand shocks rather than by technology shocks. Consumption demand shocks, however, may also not generate a leading consumption series. If responses of output to consumption shocks do not display a delayed multiplier effect, output would appear to coincide with consumption rather than lagging consumption. Therefore, a multiplier-accelerator like endogenous propagation mechanism seems essential to explain the lead-lag pattern of the business cycle. Recall that output in the US economy has a hump-shaped impulse response pattern with respect to demand shocks. When output responses to shocks are hump-shaped, output may appear to lag consumption if the main source of shocks comes from consumption demand. A potential problem is that consumption shocks may generate countercyclical movements in investment due to crowding out. Our indeterminate RBC model, however, solves not only the hump-shaped response problem, but also the crowding-out problem.

\subsection{Calibrated Analysis}

Using the same calibrated parameters as in the previous sections for the indeterminate capacity utilization model, table 8 presents the predicted correlations between consumption and output under consumption demand shocks for various leads and lags, as well as the correlations between consumption and investment for various leads and lags (standard errors in parentheses). The version of the model driven by consumption demand shocks alone $\left(\Delta_{t}\right)$ is presented in the top panel. It indicates that consumption leads output by one quarter (at $k=-1$ ) and leads investment by two quarters (at $k=-2$ ). The bottom panel presents the version of the model when there are both consumption demand shocks and sunspot shocks (the relative standard deviations of the two types of shocks are chosen so that the model passes the $Q$-test as shown in table 2 , row 4 ). It shows that adding more sources of demand shocks does not alter the qualitative predictions of the model. ${ }^{33}$

\footnotetext{
${ }^{32}$ By the same token, permanent technology shocks does not make consumption lead output. Our analysis shows that consumption appears to coincides with output and lag investment in the KPR model when technology shocks are permanent.

${ }^{33}$ The same results also hold if we add i.i.d. government spending shocks into the model. What is crucial for generating the correct lead-lag relationship between consumption and output is the presence of serially correlated consumption demand shocks.
} 
Table 8. Predicted Correlations at Business Cycle Frequency (8-40 quarters)

\begin{tabular}{lccccccccc}
\hline \hline & $k=4$ & $k=3$ & $k=2$ & $k=1$ & $k=0$ & $k=-1$ & $k=-2$ & $k=-3$ & $k=-4$ \\
\cline { 2 - 9 }$\Delta_{t}$ & & & & & & & & & \\
$\operatorname{Cor}\left(c_{t+k}, y_{t}\right)$ & .004 & .136 & .307 & .494 & .660 & .751 & .741 & .620 & .398 \\
& $(.213)$ & $(.209)$ & $(.185)$ & $(.142)$ & $(.089)$ & $(.054)$ & $(.063)$ & $(.082)$ & $(.086)$ \\
$\operatorname{Cor}\left(c_{t+k}, i_{t}\right)$ & -.015 & .088 & .235 & .409 & .578 & .687 & .704 & .610 & .409 \\
& $. .216)$ & $(.216)$ & $(.198)$ & $(.160)$ & $(.109)$ & $(.071)$ & $(.075)$ & $(.096)$ & $(.104)$ \\
$\Delta_{t}, s_{t}$ & & & & & & & & & \\
$\operatorname{Cor}\left(c_{t+k}, y_{t}\right)$ & .028 & .151 & .308 & .477 & .624 & .699 & .681 & .561 & .351 \\
& $. .205)$ & $(.205)$ & $(.190)$ & $(.157)$ & $(.114)$ & $(.083)$ & $(.083)$ & $(.098)$ & $(.107)$ \\
$\operatorname{Cor}\left(c_{t+k}, i_{t}\right)$ & .011 & .107 & .239 & .394 & .542 & .632 & .639 & .545 & .356 \\
& $(.207)$ & $(.211)$ & $(.202)$ & $(.175)$ & $(.135)$ & $(.101)$ & $(.097)$ & $(.112)$ & $(.122)$ \\
\hline
\end{tabular}

Note: Numbers in parentheses are standard errors based on 500 simulations.

\subsection{Caveat}

Aggregate investment in the U.S. is often defined as the sum of residential investment and non-residential investment. Aggregate investment so defined appears to coincide with consumption rather than lagging consumption. This is so simply because residential investment strongly leads output and business investment. The intriguing question, therefore, is why residential investment leads the business cycle? We think the answer may be that residential housing is, at least in part, a durable consumption good, not a capital good. Hence, the question is akin to the same puzzle addressed in this section.

\section{Conclusion}

Technology changes are arguably the single most important source of long-term economic growth. The recent literature, however, has questioned the notion that technology changes are also the main source of economic fluctuations. In this paper we show that equilibrium business cycle theories need not to rely on technology shocks to explain economic fluctuations. In an indeterminate RBC model with capacity utilization and mild increasing returns to scale, demand shocks can play a pivotal role in explaining actual economic fluctuations. Our analysis thus brings the real business cycle theory into closer conformity not only with the predictions of the Keynesian theory, but also with the actual data. 


\section{References}

[1] D. Andolfatto, 1996, Business cycles and labor-market search, American Economic Review 86 (March), 112-132.

[2] S. Basu and J. Fernald, 1997, Returns to scale in US production: estimates and implications, Journal of Political Economy 105 (April), 249-283.

[3] M. Baxter and R. King, 1991, Productive externalities and business cyclicles, Discussing Paper 53, Federal Reserve Bank of Minneapolis.

[4] M. Baxter and R. King, 1995, Measuring business cycles: Approximate band-pass filters for economic time series, NBER working paper 5022.

[5] J. Benhabib and R. Farmer, Indeterminacy and increasing returns, Journal of Economic Theory 63 (1994), 19-41.

[6] J. Benhabib and Y. Wen, 2000, Indeterminacy, aggregate demand, and the real business cycle, Working Paper, New York University.

[7] B. S. Bernanke, M. Gertler and S. Gilchrist, 1999, The financial accelerator in a quantitative business cycle framework, in Handbook of Macroeconomics, eds. J. Taylor and M. Woodford, Elsevier, volume 1C, 1341-1393.

[8] O. Blanchard, 1989, A traditional interpretation of macroeconomic fluctuations, American Economic Review 79 (No 5) 1146-1163.

[9] O. Blanchard, 1993, Consumption and the recession of 1990-1991, American Economic Review 93 (May), 270 - 273.

[10] O. Blanchard and D. Quah, 1989, The dynamic effects of aggregate demand and supply disturbances, American Economic Review 79, 655-673.

[11] C. Burnside and M. Eichenbaum, 1996, Factor hoarding and the propagation of business cycle shocks, American Economic Review 86 (December), 1154-1174.

[12] C. Burnside, M. Eichenbaum and S. Rebelo, 1993, Labor hoarding and the business cycle, Journal of Political Economy 101, 245-273.

[13] C. Carlstrom and T. Fuerst, 1997, Agency costs, net worth, and business fluctuations: A computable general equilibrium analysis, American Economic Review 87 (December), 893-910.

[14] J. Cochrane, 1994, Shocks, Carnegie-Rochester Conference Series on Public Policy 41, 295-364.

[15] T. Cogley and J. Nason, 1995, Output dynamics in real-business-cycle models, American Economic Review 85, 492-511. 
[16] F. Dufourt, 2000, Dynamic general equilibrium models and the Beveridge-Nelson facts, Working Paper, EUREQUA - University of Paris 1.

[17] C. Evans, 1992, Productivity shocks and real business cycles, Journal of Monetary Economics 29, 191-208.

[18] R. Farmer, Macroeconomics of Self-fulfilling Prophecies, Second Edition, 1999, The MIT Press.

[19] R. Farmer and J. T. Guo, 1994, Real business cycles and the animal spirits hypothesis, Journal of Economic Theory 63, 42-72.

[20] R. Gordon, 1993, Are procyclical productivity fluctuations a figment of measurement error? Manuscript, Northwestern University.

[21] J. Greenwood, Z. Hercowitz and G. Huffman, 1988, Investment, capacity utilization, and the real business cycle, American Economic Review 78, 402-417.

[22] Hansen, G., 1985, Indivisible labour and the business cycle, Journal of Monetary Economics 16, 309-325.

[23] Harvey, A. C., 1993, Time Series Models, second edition, published by Harvester Wheatsheaf.

[24] King, R., C. Plosser and S. Rebelo, 1988, Production, growth and business cycles: I. The basic neoclassical model, Journal of Monetary Economics 21, 195-232.

[25] G. Mankiw, 1989, Real business cycles: A new Keynesian perspective, Journal of Economic Perspectives 3, 79-90.

[26] J. Rotemberg and M. Woodford (1996), Real-business-cycle models and the forecastable movements in output, hours, and consumption, American Economic Review 86 (March), 71-89.

[27] S. Schmitt-Grohe, 2000, Endogenous business cycles and the dynamics of output, hours, and consumption, American Economic Review 90, No 5, 1136-1159.

[28] L. Summers, 1986, Some skeptical observations on real business cycle theory, Federal Reserve Bank of Minneapolis Quarterly Review, Fall, 23-27.

[29] Y. Wen, 1995, Where's the beef? The trivial dynamics of real business cycle models, Manuscript, The University if Iowa.

[30] Y. Wen, 1998, Capacity utilization under increasing returns to scale, Journal of Economic Theory 81, 7-36.

[31] Y. Wen, 2002, The business cycle effects of Christmas, Journal of Monetary Economics (forthcoming). 
A1. Outout Response to Demand
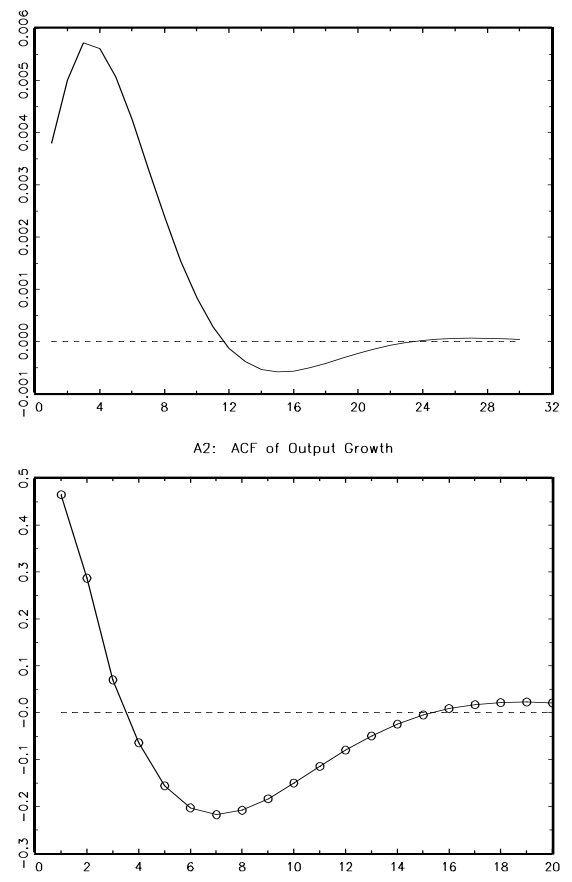

B1: Investment Response to Demand

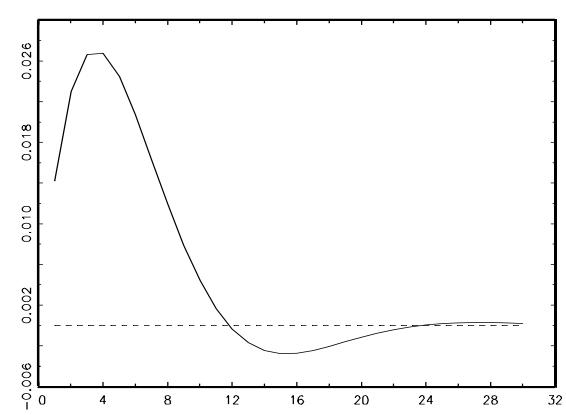

B2: ACF of Invst Growth

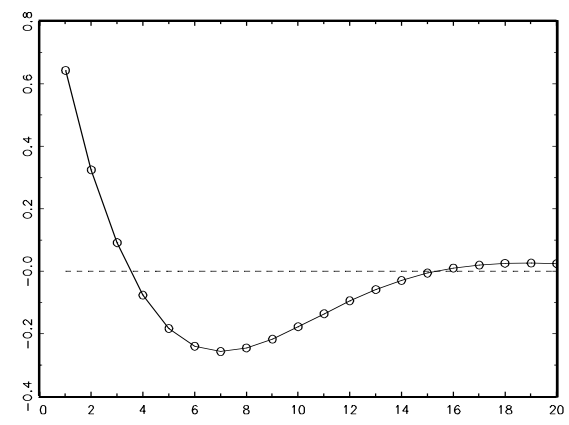

Fig. 1. Responses of Output and Investment to Transitory Shocks (US 1960:1 1994:4) 
A1. Response of $Y$
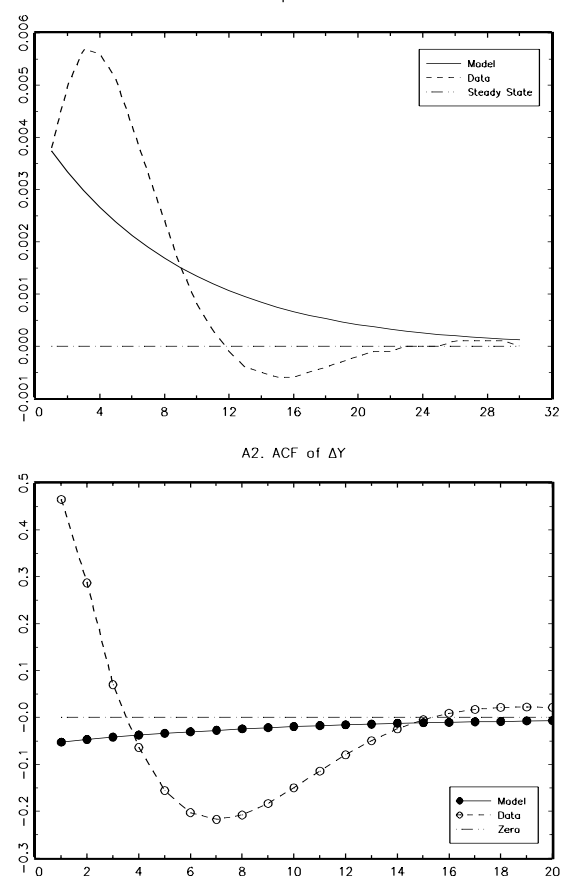

B1. Response of 1
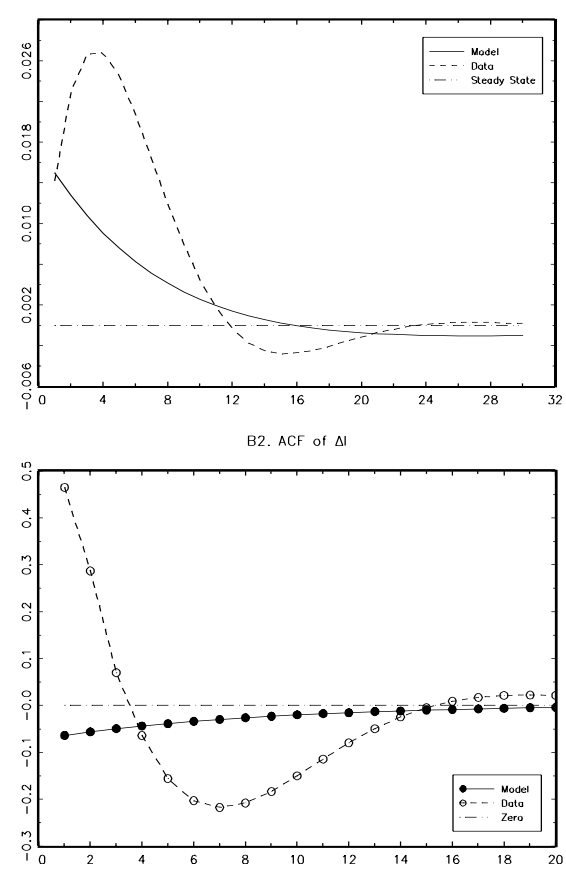

Fig. 2. Predictions of a Standard RBC model (Solid lines represent model, dashed lines represent U.S. data). First row shows impulse responses of $y_{t}$ and $i_{t}$ to demand shocks. Second row shows the implied ACF of growth rates. 
Impulse response of $Y$

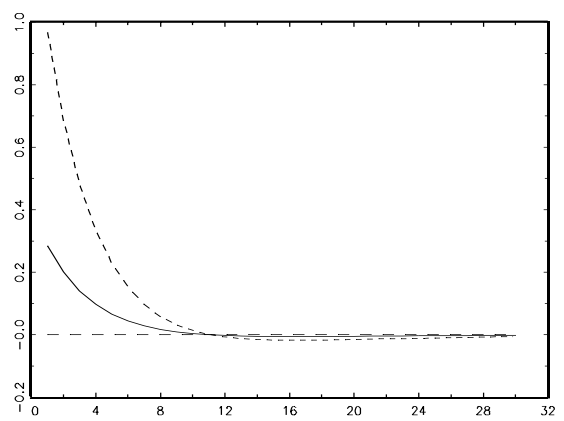

Impulse response of

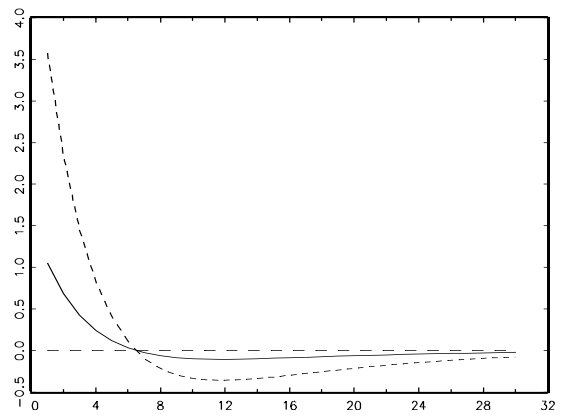

Impulse response of $C$

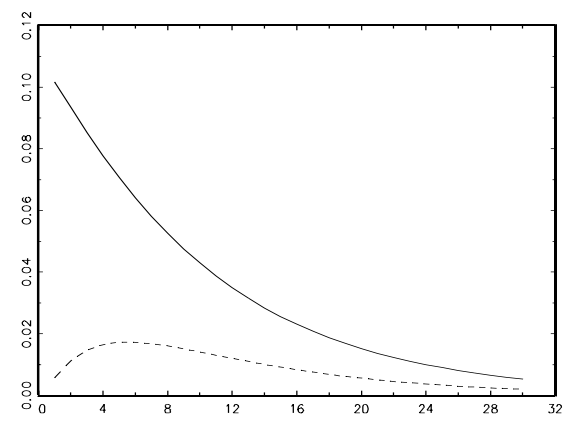

Impulse response of $\mathrm{N}$

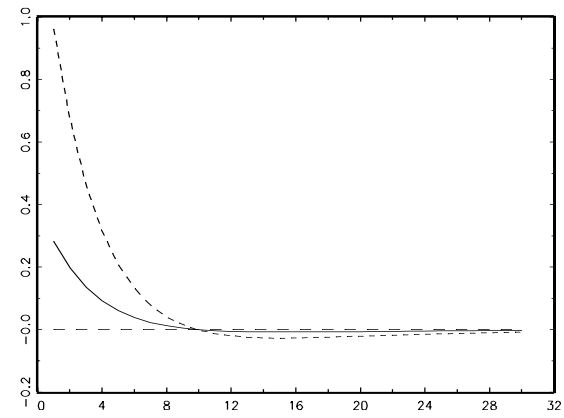

Fig. 3. Impulse Responses of $y, c, i$, and $n$ to consumption demand shocks and government spending shocks when $\eta=0.1$. Solid lines are responses to a consumption shock, dashed lines are responses to a government shock. 
Impulse response of $Y$

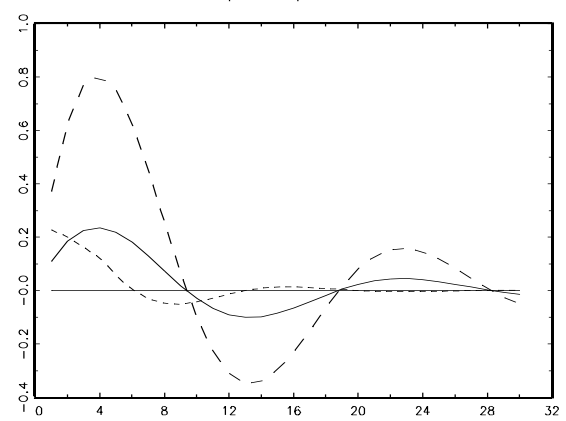

Impulse response of

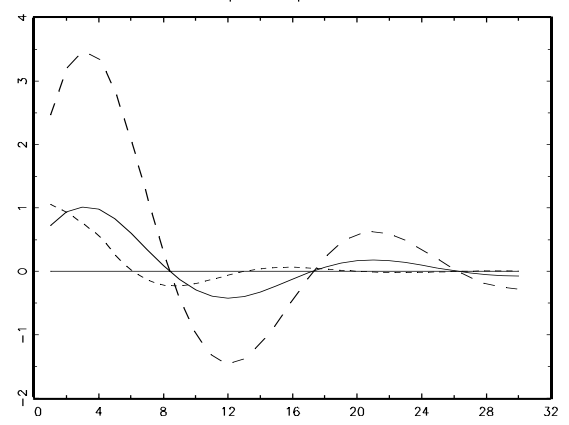

Impulse response of $C$

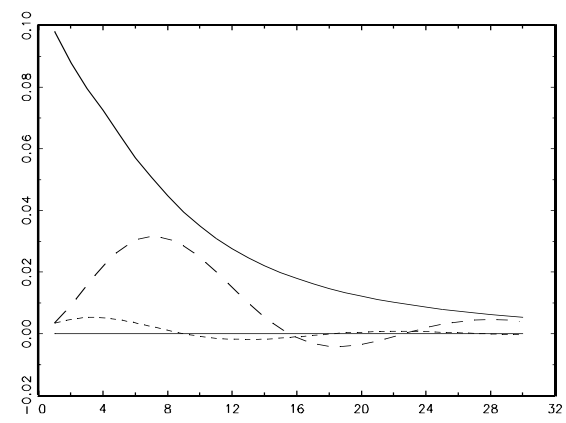

Impulse response of $\mathrm{N}$

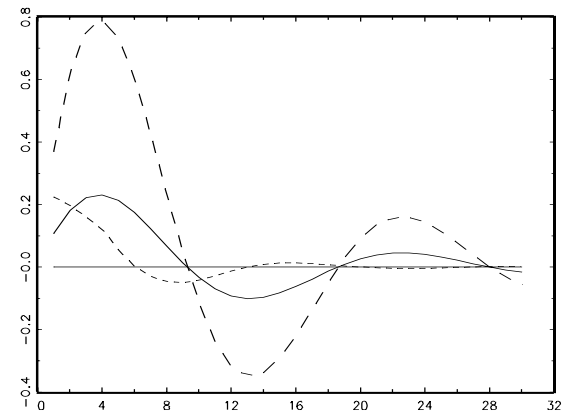

Fig. 4. Impulse Responses of $y, c, i$, and $n$ to three types of demand shocks when $\eta=0.11$. Solid lines are responses to a consumption shock; long dashed lines are responses to a government shock; short dashed lines are responses to a sunspot shock. 
Predicted Impulse Response of $y$

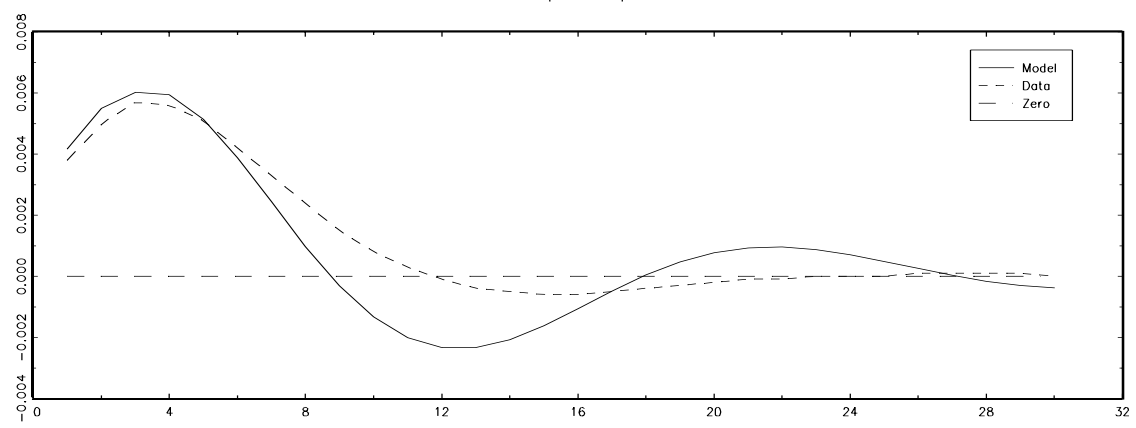

Predicted ACF of Output Growth

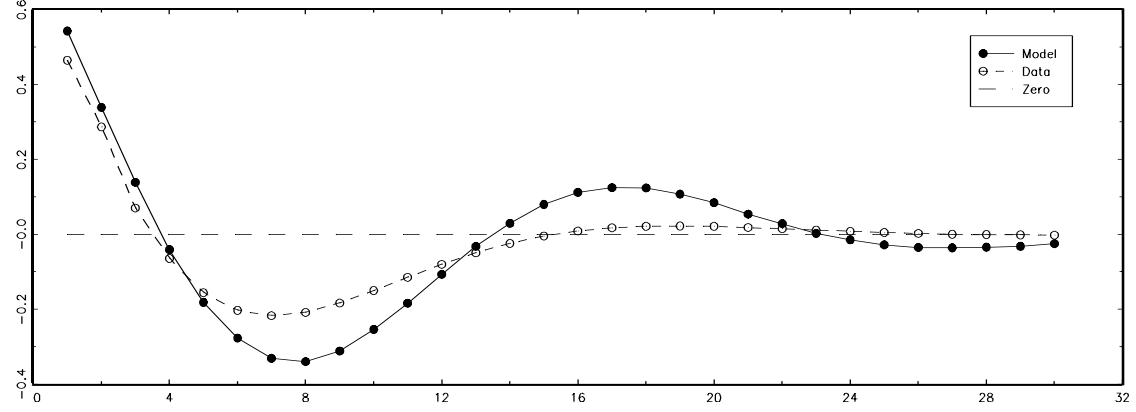

Fig. 5. Predictions of the Capacity Utilization Model with Mixed Demand Shocks (solid lines). Upper window shows the predicted impulse response function of output. Lower window shows the predicted autocorrelation function of output growth (dashed lines are U.S. data). 